\title{
Long-term tapering regimen of prednisolone for the initial episode of nephrotic syndrome
}

\author{
Shenal Thalgahagoda ${ }^{1}$, Umeshi Ishanthika Karunadasa ${ }^{1}$, Sanath Thushara Kudagammana ${ }^{1}$, Shamali \\ Abeyagunawardena ${ }^{2}$, Heshan Jayaweera ${ }^{1}$, *Asiri Abeyagunawardena ${ }^{1}$
}

Sri Lanka Journal of Child Health, 2017; 46(4): 331-336

Background: Childhood nephrotic syndrome (NS) has a relapsing-remitting course resulting in a significant corticosteroid burden or a prescription of cytotoxic immunosuppressive therapy. The ideal steroid regimen for the initial episode remains elusive.

Objective: This study was conducted at a single centre to assess the outcome of a longer regimen of prednisolone for the initial episode of childhood NS in comparison to the shorter regimen used earlier.

Methods: The clinical records of children with NS were stored manually since 1994 and electronically since 2002. From 1994 to 2002 all patients attending with the initial episode of NS were prescribed $60 \mathrm{mg} / \mathrm{m}^{2}$ prednisolone for 4 weeks followed by $40 \mathrm{mg} / \mathrm{m}^{2}$ on alternate days for 4 weeks (short term therapy / ST). From 2002 the initial episode was treated with $60 \mathrm{mg} / \mathrm{m}^{2}$ prednisolone for 4 weeks, followed by $60 \mathrm{mg} / \mathrm{m}^{2}$ on alternate days for 2 weeks tapering by $10 \mathrm{mg} / \mathrm{m}^{2}$ every 2 weeks over a period of 12 weeks (long term therapy / LT). The outcome of patients treated with ST over a period of 8 years was compared with patients treated with LT for 8 years.

Results: Fifty eight children were treated with ST and 112 with LT. The relapse rate with LT was $12.4 \%$ at 6 months, $30.5 \%$ at 12 months and $48 \%$ at 24 months of the study compared to the $31.5 \%$ at 6 months $61 \%$ at 12 months and $81 \%$ at 24 months for $\mathrm{ST}$. The mean time period for the first relapse to occur was 22.8 months for LT, whereas this was 12.5 months for ST.

Conclusion: A long term tapering regimen is superior in maintaining sustained remission compared to short term therapy for the first episode of childhood NS.

${ }^{1}$ Faculty of Medicine, University of Peradeniya, Sri Lanka, ${ }^{2}$ Teaching Hospital Peradeniya, Sri Lanka

*Correspondence: asiriabey26@gmail.com

(Received on 17 February 2017; Accepted after revision on 17 March 2017)

The authors declare that there are no conflicts of interest

Personal funding was used for the project.

Open Access Article published under the Creative

Commons Attribution CC-BY (cc)
DOI: http://dx.doi.org/10.4038/sljch.v46i4.8380

(Keywords: Childhood nephrotic syndrome, tapering prednisolone, relapse, remission)

\section{Introduction}

Childhood nephrotic syndrome (NS), the most common paediatric glomerular disease, is characterised by a tetrad comprising heavy proteinuria, hypoalbuminaemia, hyperlipidaemia and generalized oedema ${ }^{1}$. Nephrotic syndrome has an incidence of 2 to 7 per 100,000 Caucasian children with a higher incidence of about 16 per 100,000 in Asian children ${ }^{2,3}$. Steroid-sensitive NS remains the predominant type of NS during childhood with $90-95 \%$ children being responsive to steroids, of whom a greater proportion have minimal change nephropathy $(\mathrm{MCN})^{4}$. The disease is characterised by a relapsing and remitting course in most children. After 8 weeks of oral corticosteroid therapy, about $80 \%$ of children will relapse, thus requiring further courses of steroids ${ }^{4}$. Complications such as sepsis, thrombosis, malnutrition, dyslipidaemia and hypovolaemia are risks associated with relapses which complicate the disease course posing a challenge to the paediatric nephrologist.

Arneil described the use of steroids to induce remission in nephrotic syndrome for the first time in $1956^{5}$. Currently, a standard prednisone regimen developed by the International Study of Kidney Disease in Children (Modified ISKDC) ${ }^{6}$ is widely used for the treatment of the initial episode. This comprises $60 \mathrm{mg} / \mathrm{m}^{2}$ per day of prednisolone for 4 weeks followed by $40 \mathrm{mg} / \mathrm{m}^{2}$ administered on alternate days for a further 4 weeks. However, due to the observation of high relapse rates associated with this regimen, several attempts have been made to use an extended duration of corticosteroids. Even though better results have been obtained with intensified steroid regimens, the associated sideeffects have questioned their potential advantage. Most such regimens use daily prednisolone for 6-8 weeks. High doses of daily prednisolone are associated with adverse effects such as hypertension, diabetes and behavioural disorders ${ }^{7,8}$. Frequent relapses, on the other hand, result in prescription of further courses of prednisolone resulting in a significant steroid burden and prescription of cytotoxic drugs with potential side- 
effects such as opportunistic infections, sterility in men and development of future malignancies ${ }^{9,10}$. Hence, the ideal steroid regimen should be capable of quick induction and maintenance of remission with minimal steroid related side effects.

Adrenocortical suppression has been identified as a potential risk factor for relapse of NS. It is well documented that over one week of daily prednisolone has the potential to cause adrenal suppression. It is therefore logical to assume that a tapering regimen will allow the adrenal axis to recover thereby reducing the risk of relapse in childhood NS.

When treated with the modified ISKDC regimen, the steroid concentration in the body would drop rather significantly when reducing from $60 \mathrm{mg} / \mathrm{m}^{2}$ daily to $40 \mathrm{mg} / \mathrm{m}^{2}$ on alternate days. Moreover, binding of prednisolone to albumin in the plasma would result in a lesser amount of unbound drug being exposed to tissues to carry out its effects with the rising levels of albumin with remission induction $^{11}$. Hence, it can be argued that while on daily prednisolone at $60 \mathrm{mg} / \mathrm{m}^{2}$, the amount of albumin-bound drug would increase due to its higher concentration, leading to a biological tapering of unbound prednisolone. Therefore, when switching to alternate-day dose of $40 \mathrm{mg} / \mathrm{m}^{2}$ the available drug would be considerably lower than expected providing a window to trigger a relapse. This can be minimised by a regimen which switches to the same $60 \mathrm{mg} / \mathrm{m}^{2}$ on alternate days instead dropping to $40 \mathrm{mg} / \mathrm{m}^{2}$. Moreover, a prolonged tapering of prednisolone can allow recovery of the adrenal axis, resulting in a longer remission period than the modified ISKDC regimen.

Since 2002, our unit, which is the largest paediatric nephrology unit in Sri Lanka, has employed the use of a longer duration tapering dose regimen for the treatment of the first episode of NS. In this study we compare this regimen with the modified ISKDC regimen which was used prior to 2002 .

\section{Objective}

This study was conducted at a single centre to assess the outcome of a longer regimen of prednisolone for the initial episode of childhood NS compared to the shorter regimen used earlier.

\section{Patients and Methods}

This study was conducted at the paediatric unit at Teaching Hospital, Peradeniya, a tertiary nephrology referral centre in Sri Lanka. The clinical records of children with NS were stored manually since 1994 and since 2002, electronically entered and regularly updated on a computerised database in accordance with the data protection act 1998 and patient confidentiality and the approval of the
Research and Ethics Committee of the Faculty of Medicine, University of Peradeniya. This database was maintained throughout by the principal author.

From 1994 to 2002 all patients attending with the initial episode of NS were prescribed the standard course recommended by the ISKDC, which is prednisolone at $60 \mathrm{mg} / \mathrm{m}^{2}$ for 4 weeks followed by $40 \mathrm{mg} / \mathrm{m}^{2}$ on alternate days for 4 weeks (ST). From 2002, as there was accumulating evidence that longer tapering regimens had higher sustained remission rates, the initial episode was treated with $60 \mathrm{mg} / \mathrm{m}^{2}$ prednisolone for 4 weeks followed by $60 \mathrm{mg} / \mathrm{m}^{2}$ on alternate days for 2 weeks tapering by $10 \mathrm{mg} / \mathrm{m}^{2}$ every 2 weeks for a period of 12 weeks (LT). The outcome of patients treated with ST during the 8 year period from 1994-2002 was compared with that of patients treated with LT for the 8 year period from 2002-2010.

All patients who displayed primary steroid resistance (failure to respond to 28 days of prednisolone at $60 \mathrm{mg} / \mathrm{m}^{2}$ ) were excluded from the analysis. Hence only initially steroid sensitive patients were studied. As steroid sensitivity correlates well with minimal change disease routine biopsies were not performed.

During the first two years, routine follow up was done on a monthly basis as the standard practice to check for recurrence of proteinuria, to assess growth parameters, and to monitor immunizations. If no relapses occurred, they were routinely reviewed every 3-6 months till 15 years. Any events i.e. serious infections, relapse episodes, prescription of other immunosuppressive drugs were regularly updated on the data base.

A patient-held health record was maintained for each patient. Parents were educated and trained to test and record urine protein excretion on a daily basis. The presence of $3+$ proteinuria for three consecutive days was considered as a relapse. Those relapsing while on alternate day prednisolone or within 2 weeks of stopping prednisolone were considered steroid dependent. Frequent relapsers were those with 2 or more relapses with the first six months of the disease or 4 or more relapses within any 12 month period. The first relapse after starting the test regimen was considered as the primary end point of the study. The number of children with steroid dependent, frequently relapsing disease and the number requiring other immunosuppressive therapy at the end of two years of follow up were compared between the two groups.

A comparison of the baseline characteristics of the 2 treatment groups is shown in Table 1. The test regimen used in the study versus the standard prednisolone regimen is shown in Figure 1. 
Table 1: Comparison of the baseline characteristics of the two treatment groups

\begin{tabular}{|l|c|c|c|}
\hline \multicolumn{1}{|c|}{ Variable } & ST $(\boldsymbol{n}=\mathbf{5 8})$ & LT $(\boldsymbol{n}=\mathbf{1 1 2})$ & $\boldsymbol{P}$ value \\
\hline Gender, male $:$ female & $39: 19$ & $76: 36$ & 0.49 \\
\hline Age (years) & $4.3 \pm 2.8$ & $4.7 \pm 3.1$ & 0.31 \\
\hline Serum albumin $(\mathrm{g} / \mathrm{dL})$ & $1.4 \pm 0.6$ & $1.5 \pm 0.5$ & 0.41 \\
\hline Total cholesterol $(\mathrm{mg} / \mathrm{dL})$ & $389 \pm 132$ & $402 \pm 123$ & 0.47 \\
\hline
\end{tabular}

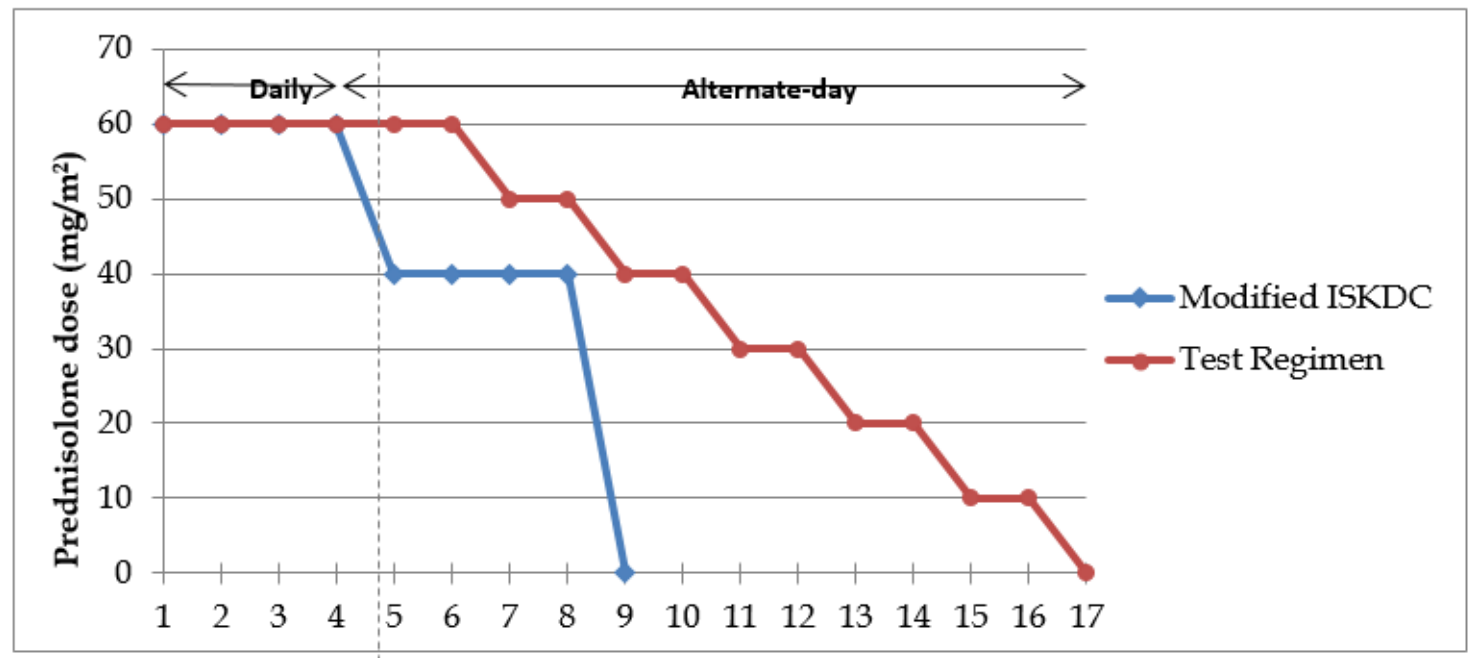

Figure 1: Test regimen used in the study versus standard prednisolone regimen

The collected variables were entered in SPSS software version 19 and analysed using descriptive statistics, paired t-test and nonparametric tests. A p value of $<0.05$ was considered significant.

\section{Results}

Fifty-eight children were treated with ST between 1994 and 2002. There were 37 (63.7\%) males and $21(36.3 \%)$ females. The age at presentation ranged from 8 months to 11.5 years and the median age was 4.8 years. One-hundred and twelve patients were treated with LT between 2002 and 2010 of which 76 $(67.9 \%)$ were males and $36(32.1 \%)$ were females. Age at presentation ranged from 9 months to 13.6 years with a median of 5.2 years.

The mean time period for the first relapse to occur was 22.8 months in the LT group compared to 12.5 months for the children who were treated with ST. The proportion who relapsed with LT was $12.4 \%$ at 6 months, $30.5 \%$ at 12 months and $48 \%$ at 24 months. These were significantly lower when compared with the children treated with ST where the corresponding proportions were $31.5 \%(\mathrm{p}=0.01)$,
$61 \%(p=0.02)$ and $81 \%(p=0.04)$ at 6,12 and 24 months respectively.

The prescription of LEV and CYC was done according to the consensus statement on management and audit potential for steroid responsive nephrotic syndrome ${ }^{12}$. If a child is relapsing frequently such children will be considered for long term alternate-day steroid therapy $0.2-0.6 \mathrm{mg} / \mathrm{kg}$. If they relapse while on $0.6 \mathrm{mg} / \mathrm{kg}$ prednisolone or have unacceptable corticosteroid related side effects they were considered for LEV therapy + alternate day steroids. If they relapse while on $0.6 \mathrm{mg} / \mathrm{kg}$ prednisolone + LEV or have unacceptable corticosteroid related side-effects they were considered for CYC therapy. FRNS patients are not steroid dependent and therefore will not receive LEV or CYC. It is the steroid dependent patient who will receive LEV or CYC. Hence 28 patients out of 58 with ST became SDNS and 17 received CYC. In the LT group of the 33 out of 112 became SDNS and 19 received CYC.

The difference between the relapse rates between ST and LT are shown in figure 2. 


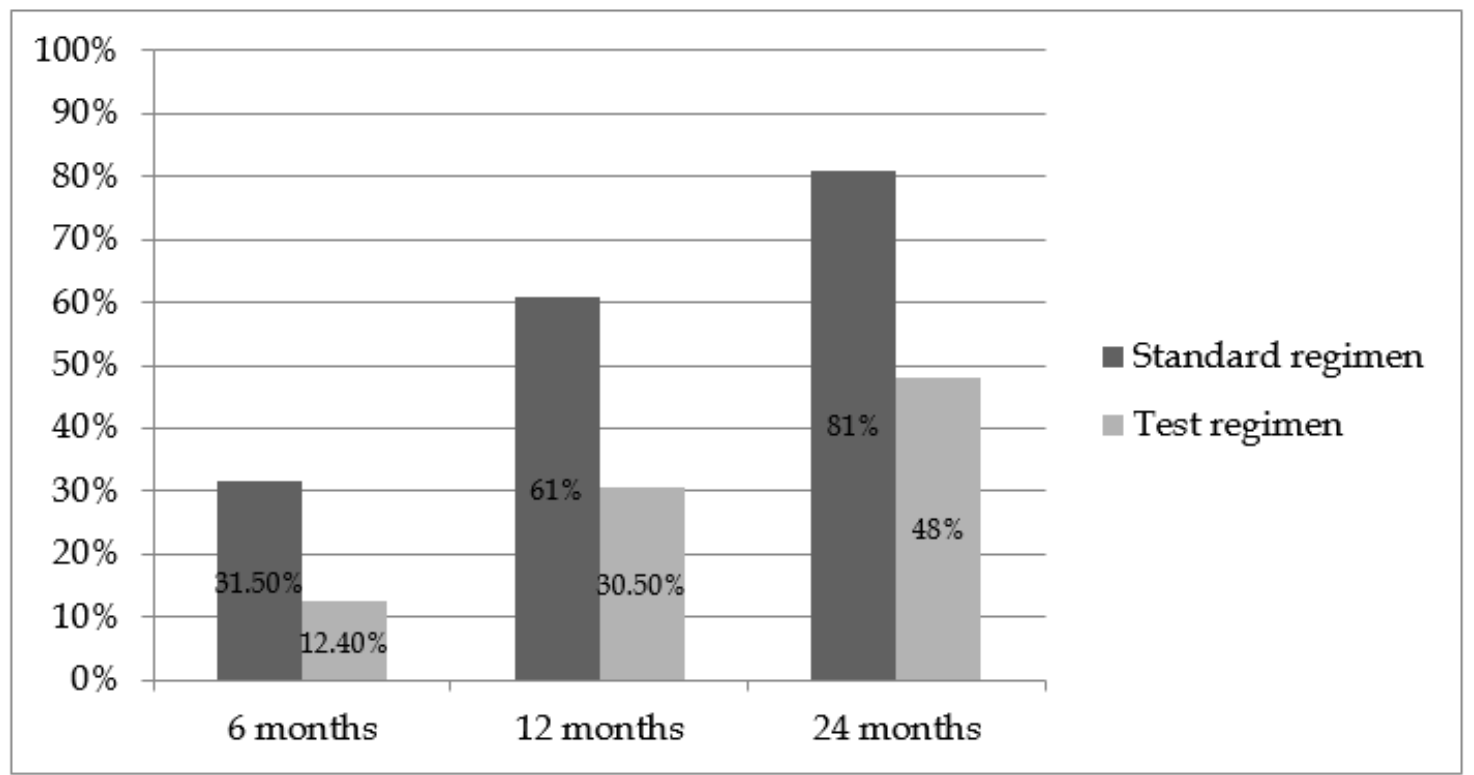

Figure 2: Comparison of relapse rates between the 2 regimens at 6,12 and 24 months

Table 2: Comparison of the outcome at 2 years between the 2 regimens

\begin{tabular}{|c|c|c|c|c|c|}
\hline \multirow[t]{2}{*}{ Regimen } & \multirow{2}{*}{\begin{tabular}{|c} 
Patients who \\
turned out to have \\
SDNS
\end{tabular}} & \multirow[t]{2}{*}{$\begin{array}{l}\text { Patients who turned } \\
\text { out to have FRNS }\end{array}$} & \multicolumn{3}{|c|}{$\begin{array}{l}\text { Patients who had to undergo immunosuppressive } \\
\text { therapy }\end{array}$} \\
\hline & & & LEV & CYC & CYA \\
\hline ST & $28 / 58(48.3 \%)$ & $12 / 58(20.7 \%)$ & $26 / 58(44.8 \%)$ & $17 / 58(29.3 \%)$ & - \\
\hline LT & $33 / 112(29.5 \%)$ & $7 / 112(6.3 \%)$ & $27 / 112(24.1 \%)$ & $19 / 112(16.9 \%)$ & $3 / 112(2.7 \%)$ \\
\hline $\mathrm{P}$ value & 0.025 & 0.025 & 0.317 & 0.083 & - \\
\hline
\end{tabular}

LEV-Levamisole, CYC-Cyclophosphamide, CYA-Cyclosporine A

As shown in table 2, the number of patients who became steroid dependent after the ST and LT was significantly different $(\mathrm{p}<0.05)$. This was true in the case of patients who had FRNS $(\mathrm{p}<0.05)$ as well. The number who needed other immunosuppressive therapy at 2 years was lower with LT compared to ST, though they did not reach statistical significance. Cyclosporine A was available since 2006 and therefore a comparison was not feasible.

\section{Discussion}

Different studies have explored the efficacy of an altered initial steroid regimen to maintain remission of $\mathrm{NS}^{13,14}$. Notable research of Ueda et al in $1988^{15}$, Ehrich and Brodehl in $1993^{16}$, Bagga et al in $1999^{17}$, Ksiek and Wyszyska in $1995^{18}$, and Jayantha in $2002^{19}$ have obtained better results with longer prednisolone courses than the standard treatment. In all these studies the number of patients who relapsed by the $6^{\text {th }}$ month was significantly less than that of the standard regimen. Lower mean relapse rates and longer sustained remission were also observed. The present study yielded similar results that are in concordance with those studies with a lesser corticosteroid burden by maintaining the daily steroid duration to 28 days and shorter alternate day tapering steroid regimen of 12 weeks. The relapse rate of patients who had LT continued to be significantly lower than those who had ST at 6, 12, and 24 months.

As this was a retrospective study, cumulative steroid doses and accurate data on side effect profiles were not available for analysis. However, the regimen used could be compared with that used in the studies of Jayantha and Ueda et al which used a tapering test regimen somewhat similar LT but slightly longer. The test regimen by Ueda et al comprised of $60 \mathrm{mg} / \mathrm{m}^{2}$ daily for 4 weeks followed by alternateday $60 \mathrm{mg} / \mathrm{m}^{2}$ for 4 weeks, then tapering the dose by $10 \mathrm{mg} / \mathrm{m}^{2}$ for 5 months. They reported no significant difference between the side effects resulting from standard and test regimens. Jayantha used a 7 month steroid regime of prednisolone $60 \mathrm{mg} / \mathrm{m}^{2}$ daily for 28 days followed by $60 \mathrm{mg} / \mathrm{m}^{2} /$ every other day for 28 days, thereafter reducing the dose by 10 $\mathrm{mg} / \mathrm{m}^{2} /$ monthly until $10 \mathrm{mg} / \mathrm{m}^{2} /$ EOD with no additional side effects and a lower cumulative steroid dose at the end of 7 months than that of the standard regimen.

However, Ehrich and Bagga reported that their longterm courses resulted in more frequent side-effects of steroid therapy. This could be attributed to the 
Long-term tapering regimen of prednisolone for the ... Sri Lanka Journal of Child Health, 2017; 46(4): 331-336

longer duration of daily prednisolone in their test regimens which resulted in a large cumulative dose. No such effect was seen from the other studies. The findings of Ksiek and Wyszyska in 1995 further support this. Out of three test regimens the course of standard treatment for 8 weeks followed by tapering the dose for another 4 months showed the best results with longer remission and reduced relapse rates. No difference in side effects was seen.

In contrast, two recent studies compared shorter courses of prednisolone with longer 6-month courses and reported that the short regimen is not inferior to long-term therapy ${ }^{20,21}$. The time before the first relapse, frequency and severity of relapse, adverse effects were also similar for both long term and short term courses. Research by Norero et al in 1996 which compared the ISKDC regimen with a 12 week prednisolone regimen also yielded similar results $^{22}$. The meta-analysis by Hodson E, et al. suggested that extension of alternate day steroid by one month reduces the risk of relapse at 2 years by $7 \%$ up to 7 months $^{3}$. The Cochrane Database Systematic Review of 2015 suggests that there are many factors that determine the risk of relapse viz. ethnic background, living standards, nutrition, immunisation and infection ${ }^{23}$.

Glucocorticoid-induced hypothalamic-pituitaryadrenal axis (HPA) suppression is a well-known side effect of steroid therapy in NS and is associated with early relapses, whereas normal adrenocortical function seems to delay the subsequent relapse ${ }^{24,25}$. This is a particularly important aspect to consider when using high steroid doses for prolonged periods. As explained above, it could be postulated that the significant reduction of the dose of prednisolone in the $5^{\text {th }}$ week and the abrupt cessation at the end of the $8^{\text {th }}$ week in the standard regimen increase the risk for a relapse.

As this is a retrospective study only the unacceptable side effects are documented in the database. Hence the side effects were not analysed. However in all studies in the published literature where the daily steroid regimen consists 28 days in the LT, no significant increase of side effects was reported. Higher side effects were reported only when daily prednisolone was prescribed for 6-8 weeks. In this cohort of patients there was no documentation of any unacceptable side effects such as cataract formation, glucose intolerance or spontaneous fracture.

Considering the outcome of the above study, the LT regimen is able to overcome the drawbacks of longer daily doses and abrupt reduction/cessation of steroid therapy. Utilising a combination of a standard course of daily prednisolone and a tapering alternate day regimen we obtained significantly lower relapse rates. Additional favourable outcomes from the LT regimen are the lower number of patients who became steroid-dependent and/or had frequentlyrelapsing disease and the lower percentages of patients who needed immunosuppressive medication.

This study is not without drawbacks. The retrospective nature is noteworthy. One could also argue that we have compared 2 different time periods. However, with the global trend in NS showing an increase in severity with time, we believe that this makes the findings of our study all the more significant as the LT regimen was used in the second time period when presumably there would have been an increase in severity. Therefore it can be concluded that long-term tapering of prednisolone is preferable in treating the initial episode of childhood NS for Sri Lankan children.

\section{References}

1. Park Shin J. Complications of nephrotic syndrome. Korean Journal of Pediatrics 2011; 54(8):322.

2. Eddy A, Symons J. Nephrotic syndrome in childhood. Lancet 2003; 362(9384):62939.

3. Hodson E, Knight J, Willis N, Craig J. Corticosteroid therapy in nephrotic syndrome: a meta-analysis of randomised controlled trials. Archives of Disease in Childhood 2000; 83(1):45-51.

4. Pravitsitthikul N, Willis NS, Hodson EM, Craig JC. Non-corticosteroid immunosuppressive medications for steroid-sensitive nephrotic syndrome in children. Cochrane Database Systematic Reviews 2013 Oct 29; (10): CD002290.

5. Arneil G. Treatment of nephrosis with prednisolone. Lancet 1956; 267(6921): 510.

6. Abramowicz M, Barnett HL, Edelmann CM Jr, Greifer I, Kobayashi O, Arneil GC, Barron BA, Gordillo-P G, Hallman N, Tiddens HA. Controlled trial of azathioprine in children with nephrotic syndrome. A report for the international study of kidney disease in children. Lancet 1970; 1(7654):959-61.

7. Niaudet P. Long-term outcome of children with steroid-sensitive idiopathic nephrotic syndrome. Clinical Journal of the 
American Society of Nephrology 2009; 4(10):1547-8.

8. Hall A, Thorley G, Houtman P. The effects of corticosteroids on behaviour in children with nephrotic syndrome. Pediatric Nephrology 2003; 18(12):1220-3.

9. Jayaweera AHHM, Abeyagunawardena A. Effectiveness and safety of cyclosporin A therapy in steroid dependent nephrotic syndrome in childhood. Sri Lanka Journal of Child Health. 2012; 41(4): 171-5.

10. Latta K, von Schnakenburg C, Ehrich J. A meta-analysis of cytotoxic treatment for frequently relapsing nephrotic syndrome in children. Pediatric Nephrology 2001; 16(3):271-82.

11. Lewis G, Jusko W, Burke C, Graves L. Prednisone side-effects and serum-protein levels. Lancet. 1971; 298(7728):778-81.

12. Consensus statement on management and audit potential for steroid responsive nephrotic syndrome. Report of a Workshop by the British Association for Paediatric Nephrology and Research Unit, Royal College of Physicians. Archives of Disease in Childhood 1994; 70(2): 151-7.

13. Hiraoka M, Tsukahara $\mathrm{H}$, Matsubara $\mathrm{K}$, Tsurusawa M, Takeda N, Haruki S et al. A randomized study of two long-course prednisolone regimens for nephrotic syndrome in children. American Journal of Kidney Disease 2003; 41(6):1155-62.

14. Arbeitsgemeinschaft Fur PadiatrischeNephrologie. Short versus standard prednisone therapy for initial treatment of idiopathic nephrotic syndrome in children. Lancet 1988; 331(8582):380-3.

15. Ueda N, Chihara M, Kawaguchi S et al. Intermittent versus long-term tapering prednisolone for initial therapy in children with idiopathic nephrotic syndrome. Journal of Pediatrics 1988; 112(1):122-6.

16. Ehrich J, Brodehl J. Long versus standard prednisone therapy for initial treatment of idiopathic nephrotic syndrome in children. ArbeitsgemeinschaftfürPädiatrischeNephr ologie. European Journal of Pediatrics 1993; 152(4):357-61.
17. Bagga A, Hari P, Srivastava R. Prolonged versus standard prednisolone therapy for initial episode of nephrotic syndrome. Pediatric Nephrology 1999; 13(9):824-7.

18. Ksiek J, Wyszyska T. Short versus long initial prednisone treatment in steroidsensitive nephrotic syndrome in children. Acta Paediatrica. 1995; 84(8):889-93.

19. Jayantha UK. Comparison of ISKDC regime with a 7 months steroid regime in the first attack of nephrotic syndrome. Pediatric Nephrology 2004; 19:C81.

20. Teeninga N, Kist-van Holthe J, van Rijswijk $\mathrm{N}$ et al. Extending prednisolone treatment does not reduce relapses in childhood nephrotic syndrome. Journal of the American Society of Nephrology 2012; 24(1):149-59.

21. Yoshikawa N, Nakanishi K, Sako M, Oba M, Mori R, Ota E et al. A multicentre randomized trial indicates initial prednisolone treatment for childhood nephrotic syndrome for two months is not inferior to six-month treatment. Kidney International 2015; 87(1):225-32.

22. Norero C, Delucchi A, Lagos E, Rosati P. Initial therapy of primary nephrotic syndrome in children: evaluation in a period of 18 months of two prednisone treatment schedules. Chilean Co-operative Group of Study of Nephrotic Syndrome in Children. Revista Medica de Chile 1996; 124(5):567-72.

23. Hahn D, Hodson EM, Willis NS, Craig JC. Corticosteroid therapy for nephrotic syndrome in children. Cochrane Database Systematic Reviews 2015 Mar 18; (3): CD001533.

24. Leisti S, Koskimies O. Risk of relapse in steroid-sensitive nephrotic syndrome: Effect of stage of post-prednisone adrenocortical suppression. Journal of Pediatrics 1983; 103(4):553-7.

25. Abeyagunawardena A, Hindmarsh $P$, Trompeter R. Adrenocortical suppression increases the risk of relapse in nephrotic syndrome. Archives of Disease in Childhood 2007; 92(7):585-8. 